\title{
Entrepreneurship Attitudes and the Big Five: A Cross-Cultural Comparison Between Spain and the United States
}

\author{
Amparo Oliver ${ }^{1 *}$, Barry H. Schneider ${ }^{2}$, Laura Galiana ${ }^{1}$, David A. Puricelli3 ${ }^{3}$, Marc Schwendemann ${ }^{4}$, and José M. Tomás ${ }^{1}$

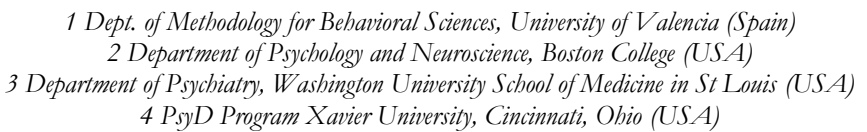

Título: Actitudes de emprendimiento y los "Cinco Grandes": una comparación intercultural entre España y Estados Unidos.

Resumen: La cultura puede interactuar con la personalidad para facilitar o inhibir las conductas emprendedoras. 296 estudiantes universitarios en Estados Unidos y 257 en España completaron el inventario de los Cinco Grandes de Personalidad y la escala de Actitudes Emprendedoras para Estudiantes (Media de edad $=20.16$ años; $D T=3.39$ ). Se hipotetiza que, a través de culturas, conciencia y apertura serán predictores de mayor toma de riesgos, mientras neuroticismo y amigabilidad lo harán en negativo. Las variables de personalidad explican una mayor proporción de varianza en actitudes emprendedoras en los datos estadounidenses. Las asociaciones entre las dimensiones de personalidad y emprendimiento varían considerablemente por país y género. Se encontraron correlaciones positivas significativas entre conciencia y toma de riesgos solo en hombres españoles. E neuroticismo correlaciona negativa y significativamente con la toma de riesgos, solo en el caso de los participantes americanos.

Palabras clave: Emprendimiento. Cinco Grandes. Toma de Riesgos. Género. Transcultural.

\section{Entrepreneurship Attitudes and the Big Five: A Cross-Cultural Comparison Between Spain and the United States}

According to one of the most accepted definitions, "entrepreneurship is a process that involves the discovery, evaluation, and exploitation of opportunities to introduce new products, services, processes, ways of organizing, or markets (Shane \& Venkataraman, 2000, p. 2)". Entrepreneurship is a tool for sustainable economic growth in many countries, but in words of Teixeira and Vasque (2020) there is a danger of 'blind' recipes to promote entrepreneurship without considering the 'entrepreneurship ecosystem' and, at a more general level, the countries' culture. Building on several previous models with fewer dimensions, Oliver and Galiana (2015) finalized six dimensions of entrepreneurial attitude: proactivity, professional ethics, empathy, innovation, autonomy, and risk taking. Personality psychologists have delved into the ways in which long-standing traits and characteristics may affect entrepreneurial intentions and consequently behaviors. Tolerance for risk taking and internal locus of control are other personality traits linked to entrepreneurial success (Brockhaus, 1980). Meta-analyses of research on the person-

* Correspondence address [Dirección para correspondencia]

Amparo Oliver. Dept. of Methodology for Behavioral Sciences, Faculty of Psychology \& Speech Therapy, Av. Blasco Ibáñez 21, 46010 Valencia (Spain). E-mail: oliver@uv.es

(Article received: 10-12-2020, revised: 18-1-2021, accepted: 2-8-2021)
Abstract: Culture may interact with personality to facilitate or inhibit entrepreneurial behaviors. 296 undergraduates in the United States and 257 in Spain completed the Big Five Personality Inventory and the Entrepreneurial Attitudes Scale for Students (Mean age $=20.16$ years; $S D=3.39$ ). We hypothesized that across cultures, conscientiousness and openness would predict greater risk taking whereas neuroticism and agreeableness would be a negative correlate. Personality variables explained a larger proportion of the variance in entrepreneurial attitudes in the U.S. data. The associations between the personality dimensions and entrepreneurship varied considerably by country and gender. Significant positive correlations were found between conscientiousness and risk taking only for Spanish men. Neuroticism was significantly and negatively correlated with risk taking only for American participants.

Keywords: Entrepreneurship. Big Five. Risk taking. Gender. Crosscultural.

ality correlates of entrepreneurial attitudes and success indicate that entrepreneurs score higher than managers on measures of conscientiousness and openness while scoring lower on measures of neuroticism, agreeableness and extraversion (Brandstätter, 2011; Zhao \& Siebert, 2006). Entrepreneurs also score higher in extraversion (Brandstätter, 2011).

\section{Culture as a Backdrop for Entrepreneurship}

It is often assumed that the characteristics of entrepreneurs identified in U.S research - risk taking, need for achievement, innovativeness, and initiative - apply to entrepreneurship in other countries (Gupta \& Fernandez, 2009). Gupta and Fernandez (2009) criticize this gratuitous transposition with a reminder that culture provides the interpretive frameworks by which individuals understand their social worlds and determine their actions within them. According to an influential review article by Hayton et al. (2002), individualism is strongly associated with entrepreneurship whereas power distance (essentially the degree of deference in a culture towards authority figures) and uncertainty avoidance (the need for clear rules and expectations) are negative correlates. Risk taking may depend not only on individual's perceptions of the ratio of risk to reward but also on tolerance for uncertainty, which is both a personality trait and a feature of cultures. Gupta and Fernandez (2009) found both similarities and differences in the characteristics attributed to hypothetical entrepreneurs by business school students in 
the U.S., India and Turkey. Participants in all three countries indicated that the need to achieve, self-reliance, curiosity, intelligence, empathy, helpfulness and logical thinking described entrepreneurs in their countries to a certain extent. However, helpfulness was rated as far more typical of entrepreneurs in Turkey and India than in the U.S., whereas awareness of the feelings of others was rated much higher by U.S. participants as a trait typical of entrepreneurs. Friendliness, cheerfulness and tactfulness, which are features that might promote relationships, were rated as far more typical of entrepreneurs in the U.S. and Turkey than in India. Additionally, from a cultural perspective, university and family, are two contexts in which students are socially embedded, and jointly influence the acquisition of entrepreneurial skills (Hahn et al., 2020).

\section{Gender Differences in Personality and Entrepre- neurship}

Most researchers have found marked gender differences in both personality and entrepreneurship. Schmitt et al. (2008) reported that across a majority of the 55 nations studied, women scored higher than men on measures of neuroticism, extraversion, agreeableness, and conscientiousness. Researchers have also found evidence for gender differences in entrepreneurship. In 52 out of 54 nations studied by Warnecke (2013), there was a higher rate of male entrepreneurs than female although in the last decades, although, women have significantly increased their participation on economic growth and job creation (Chatterjee et al., 2018). The results of multiple studies have shown that across cultures, men engage in more risk-taking behaviors than women (e.g. Byrnes et al., 1999). In a comparison of the U.S. and Spain, Schmitt et al. (2008) found a larger gender gap in Spain than in the United States for neuroticism, extraversion, and conscientiousness, with women scoring higher than men on all three traits.

\section{Personality and Entrepreneurship in Spain and the U.S.}

Several focused comparisons of personality data obtained from Spanish and U.S. samples highlight some subtle but important differences. A series of cluster analyses of data from many nations reveals that, Spanish people, on the average, score lower than those from the United States in the Big Five dimensions of agreeableness and conscientiousness while scoring higher on neuroticism (Schmitt et al., 2007). In another data set from 36 countries, cluster analysis indicated that Spaniards are higher in neuroticism and lower in extraversion than the US sample (Allik \& McCrae, 2004).

Similar trends have emerged from studies conducted specifically with entrepreneurs. In a comprehensive review of research on the managerial culture of Spain, O'Connell et al. (2007) reported that middle managers in Spain, when compared with middle managers in 60 other countries, ranked relatively high in assertiveness but also very high in power distance and in-group collectivism. A high degree of in-group collectivism can also be inferred from Laurent's (1980) observation that the Latin countries of Southern Europe are characterized by a more social view of the organization than the more instrumental view common in the United States and Southern Europe.

\section{Gender and Entrepreneurship in Spain}

Spain has traditionally been considered a society with marked gender differences in many respects. While Spanish women on average reach higher levels of education than men, there have not been corresponding increases in financial gains (Moral-Arce et al., 2012). According to Rico and Cabrer-Borrás (2018), about 85\% of the gender gap in Spanish entrepreneurship can be attributed to unobservable cultural and structural factors that are representative of discriminatory societal perceptions. Despite the persistence of the gender gap in the workplace, it is undeniable that the women's movement has had a market impact on Spanish society. Bustelo (2016) documents in detail the legislation that has been passed to guarantee gender equality and establish a number of official bodies to oversee that process.

\section{Entrepreneurship and the Health of the National Economy}

The economies of Spain and the United States also differ in ways that are relevant to the study of entrepreneurship. Due to extensive government involvement in the Spanish economy, it has been classified as highly regulated while the United States economy is considered lightly regulated (Acemoglu \& Pischke, 1998).

In Weber's (2013) cross-cultural data, Americans perceive themselves as highly risk tolerant while Spanish people consider themselves to be relatively risk averse (Weber, 2013). Researchers have also found that business managers in Spain have a low level of risk tolerance (Chhokar et al., 2007). Not all findings, however, have been consistent with the idea that people from the United States are more risk tolerant than people from Spain; Zinkhan and Kanande (1991) found a sample of Spanish students to be less risk averse than American students. It is logical to expect that risk taking depends on tolerance for ambiguity and uncertainty, which is one of the core features of cultures in Hofstede's (2001) scheme. Spain, together with most other European countries, differ sharply from the U.S. in that regard. Spain's masculinity score is 42 compared with 62 for the U.S. In Hofstede's typology, more masculine cultures emphasize ambition and differentiated gender roles. It should be noted that, although the masculinity score for Spain is higher than that of the U.S., Spain scores higher than most of the Northern European cultures.

There are a number of practical implications of the exploration of individual differences in entrepreneurial beliefs 
and behavior, especially individual differences in terms of culture and gender. First of all, educational counselors at the secondary-school and university levels should be aware of the fact that people tend to be satisfied in careers that are consistent with their personalities but dissatisfied in careers that are inconsistent with their personal needs, dispositions, and beliefs (Zhao et al., 2010). To the extent that gender influences such individual characteristics, educators must ensure that they do not dissuade girls and women from careers involving risk taking and entrepreneurial activity if such activity is consistent with their aspirations and personalities. University programs in areas in which entrepreneurial activity is possible, such as engineering, can incorporate into their curricula activities designed to promote entrepreneurial skill and comfort with entrepreneurial activity (Ferreras-García et al., 2020). Finally, business professionals need to be aware of gender and cultural differences, as they may interact with differences in personality during their interactions with colleagues in different countries.

\section{Hypotheses}

Our hypotheses were as follows:

- Hypothesis 1: Across cultures, higher scores on conscientiousness and openness will predict higher scores on risk taking.

- Hypothesis 2: Across cultures, higher scores on neuroticism and agreeableness will predict lower scores on risk taking.
- Hypothesis 3: Risk taking scores will be higher in the U.S. sample than in the Spanish sample.

Although examining gender and gender culture differences was one of our main objectives, we refrained from proposing directional hypotheses regarding gender and regarding gender $\mathrm{x}$ culture effects on entrepreneurship because the literature on gender roles in Spain documents both traditional expectations and pronounced recent change, as discussed earlier, making any prediction about gender differences quite speculative.

\section{Methods}

\section{Participants and Procedure}

The participants were undergraduate university students from Boston College in the United States and the University of Valencia in Spain. Respondents in both countries participated anonymously and voluntarily online. Details on sample composition can be seen in Figure 1. There were 296 American participants $(M$ age $=19.02$ years; $S D=1.07)$, with $69.6 \%$ being women $(M$ age $=18.92$ years, $S D=0.90)$ and $30.4 \%$ for men $(M$ age $=19.26$ years, $S D=1.37)$. For the Spanish sample, participants were recruited during their university classes. The Spanish sample consisted of 257 students ( $M$ age $=21.4$ years, $S D=4.48)$, with $68.1 \%$ being women $(M$ age $=20.98$ years, $S D=3.33)$ and $31.9 \%$ men $(M$ age $=$ 22.41 years, $S D=6.19)$.

Figure 1

Composition of total sample by gender and country.

Total sample $=553$

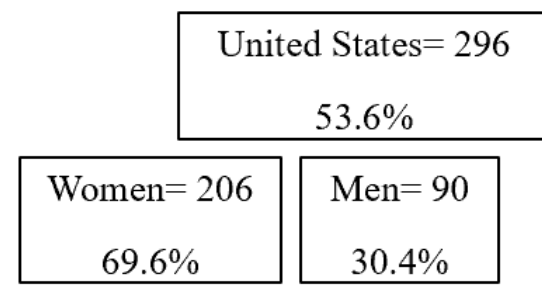

All procedures were in accordance with the ethical standards of the two participant universities. The approval of the ethic committee was obtained from Institutional Review Board (IRB) with reference 16.098.01B "Cross-Cultural Study of Entrepreneurial Attitudes and Personality". Informed consent was obtained online from all participants. Participants were informed the cross-cultural study ValenciaBoston was reviewed by the Boston College IRB and its approval was granted. The online "Consent Given" button below was used.

\section{Instruments}

The Big Five Inventory

In order to provide information on enduring personality traits, participants completed the Big Five Inventory. The original version given to American participants was developed by John and Srivastava (1999). We used the published Spanishlanguage version (Benet-Martínez \& John, 1998) in Spain. It includes 44 items used to assess extraversion, agreeableness, conscientiousness, neuroticism, and openness. Alphas for 
each country (Spain in parentheses) were $.86(.82)$ for extraversion, $.80(.70)$ for agreeableness, $.80(.78)$ for conscientiousness, .83 (.81) for neuroticism, and .78 (.76) for openness. Items use a 1 "disagree", 3 "neutral" to 5 "agree" scale.

Escala de Actitudes Emprendedoras para Estudiantes (EAEE) (Entrepreneurial Attitudes Scale for Students)

In order to provide information on entrepreneurial traits, participants completed the EAEE, a scale developed by Oliver and Galiana (2015). The original authors developed both English and Spanish versions. The scale provides scores for six different dimensions of entrepreneurial attitudes: proactivity, professional ethics, empathy, innovation, autonomy, and risk taking. Internal consistency coefficients on the various dimensions for each country's sample (Spain in parentheses) were $.70(.62)$ for proactivity, $.79(.79)$ for professional ethics, .82 (.85) for empathy, .88 (.91) for innovation, .82 (.77) for autonomy, and .73 (.73) for risk taking. The scale contains 18 items (3 per dimension), with a 1 "disagree strongly" to 7 "agree strongly" response scale.

\section{Analyses}

Analyses included descriptive statistics, zero-order correlations, internal consistency estimates, multivariate analyses of variance (MANOVA) and several structural equation models relating personality dimensions and entrepreneurship attitudes.

Structural models were estimated in Mplus 8.2 (Muthén \& Muthén, 1997-2018) with Robust Maximum Likelihood to accommodate non-normality (Finney \& DiStefano, 2013). Model fit was assessed using several tests and indexes (Kline, 2015), including the chi-square statistic, a Comparative Fit Index (CFI) of more than .90 (and ideally greater than .95) to indicate good fit, a Root Mean Squared Error of Approximation (RMSEA) and the Standardized Root Mean Squared Residuals (SRMR) with values of .08 or less (and ideally less than .05) indicating excellent fit. This overall model fit was accompanied by a careful diagnosis of parameter estimates in order to avoid using the aforementioned thresholds blindly (Kline, 2015).

For group mean comparisons, a MANOVA with two factors, gender and country, and six dependent variables was carried out. Pillai's criterion test, the most robust test to violations assumptions was used.

\section{Results}

\section{Descriptive Statistics}

Means and standard deviations for both personality and entrepreneurship for both countries and then divided by gender are presented in Table 1.

Table 1

Descriptive statistics for the personality and entrepreneurial dimensions by country and gender.

\begin{tabular}{|c|c|c|c|c|c|c|}
\hline \multirow[b]{2}{*}{ Variables } & Mean & $\mathrm{SD}$ & Mean & $\mathrm{SD}$ & Mean & SD \\
\hline & \multicolumn{2}{|c|}{ USA total } & \multicolumn{2}{|c|}{ USA males } & \multicolumn{2}{|c|}{ USA females } \\
\hline Extraversion & 3.15 & 0.82 & 3.13 & 0.74 & 3.16 & 0.85 \\
\hline Agreeableness & 3.58 & 0.38 & 3.76 & 0.55 & 3.94 & 0.63 \\
\hline Conscientiousness & 3.53 & 0.64 & 3.34 & 0.59 & 3.63 & 0.65 \\
\hline Neuroticism & 3.14 & 0.77 & 2.76 & 0.74 & 3.32 & 0.72 \\
\hline Openness to experience & 3.58 & 0.60 & 3.64 & 0.60 & 3.56 & 0.61 \\
\hline Proactivity & 5.55 & 1.03 & 5.23 & 1.23 & 5.69 & 0.94 \\
\hline Professional ethics & 5.68 & 1.03 & 5.56 & 1.08 & 5.74 & 1.01 \\
\hline Empathy & 6.20 & 0.91 & 5.83 & 0.99 & 6.37 & 0.82 \\
\hline Innovation & 4.97 & 1.28 & 5.17 & 1.34 & 4.89 & 1.26 \\
\hline Autonomy & 5.69 & 1.00 & 5.65 & 1.06 & 5.72 & 0.97 \\
\hline \multirow[t]{2}{*}{ Risk taking } & 4.97 & 1.20 & 5.21 & 1.18 & 4.87 & 1.20 \\
\hline & \multicolumn{2}{|c|}{ Spain total } & \multicolumn{2}{|c|}{ Spain males } & \multicolumn{2}{|c|}{ Spain females } \\
\hline Extraversion & 3.43 & 0.76 & 3.28 & 0.81 & 3.50 & 0.74 \\
\hline Agreeableness & 3.14 & 0.35 & 3.65 & 0.70 & 3.86 & 0.53 \\
\hline Conscientiousness & 3.48 & 0.58 & 3.44 & 0.55 & 3.50 & 0.59 \\
\hline Neuroticism & 2.82 & 0.76 & 2.54 & 0.69 & 2.96 & 0.75 \\
\hline Openness to experience & 3.61 & 0.58 & 3.63 & 0.61 & 3.61 & 0.58 \\
\hline Proactivity & 5.71 & 0.87 & 5.63 & 0.87 & 5.75 & 0.88 \\
\hline Professional ethics & 5.73 & 0.86 & 5.94 & 0.87 & 5.64 & 0.84 \\
\hline Empathy & 6.16 & 0.79 & 5.99 & 0.99 & 6.24 & 0.67 \\
\hline Innovation & 5.01 & 1.15 & 5.42 & 1.14 & 4.83 & 1.11 \\
\hline Autonomy & 5.62 & 0.79 & 5.70 & 0.81 & 5.59 & 0.78 \\
\hline Risk taking & 5.37 & 0.98 & 5.35 & 1.06 & 5.40 & 0.98 \\
\hline
\end{tabular}




\section{Path Analysis}

Table 2 contains the Pearson product-moment correlations among the variables used in the path analysis. The initial model simply states that all personality dimensions may predict the entrepreneurship dimensions. However, if all effects of predictors of the dependent variables are estimated simultaneously with all inter-correlations among predictors and all correlations among the dependent variables, the model does not have sufficient degrees of freedom and it is not testable. Therefore, we started the sequence of structural models with a simplified model in which all effects of predictors on dependent variables were estimated, but all covariances (correlations) among predictors and covariances (correlations) among dependent variables were set to zero. Once we tested this initial model, we made statistical changes according to two strategies: a) setting all the effects that were not statistically significant to zero; and b) adding the correlations among predictors and among the dependent variables that had large (and statistically significant) Modification Indexes. This led to the final model (see Figure 2).

Table 2. Pearson product-moment correlations between personality and entrepreneurship attitudes.

\begin{tabular}{|c|c|c|c|c|c|c|c|c|c|c|c|}
\hline & Extra & Agree & Consc & Neuro & Open & Proac & Prof & Emp & Inn & Aut & Risk \\
\hline Extra & - & $.29 * *$ & $.17^{* *}$ & -.09 & $.21 * *$ & $.17 * *$ & $.31^{* *}$ & $.26^{* *}$ & $.20 * *$ & $.18^{* *}$ & $.26 * *$ \\
\hline Agree & -.01 & - & $.27 * *$ & $-.26 * *$ & .06 & .07 & .08 & $.37 * *$ & -.06 & .05 & .09 \\
\hline Consc & $.18^{* *}$ & $.46^{* *}$ & - & .01 & .09 & .11 & $.31^{* *}$ & $.18^{* *}$ & $.15^{*}$ & $.20 * *$ & $.16^{* *}$ \\
\hline Neuro & $-.27 * *$ & $-.29 * *$ & $-.19 * *$ & - & -.08 & -.09 & $-.18^{* *}$ & -.12 & -.10 & -.03 & -.05 \\
\hline Open & .10 & .07 & .01 & -.05 & - & $.20 * *$ & $.16^{* *}$ & $.15^{*}$ & $.33 * *$ & $.30 * *$ & $.23^{* *}$ \\
\hline Proac & $.17^{* *}$ & $.23^{* *}$ & $.30^{* *}$ & -.04 & .08 & - & $.37 * *$ & $.16^{*}$ & $.29 * *$ & $.34 * *$ & $.21 * *$ \\
\hline Prof & $.31 * *$ & $.33^{* *}$ & $.57^{* *}$ & $-.20 * *$ & $.12^{*}$ & $.60 * *$ & - & $.27^{* *}$ & $.43^{* *}$ & $.42 * *$ & $.31 * *$ \\
\hline Emp & .09 & $.53 * *$ & $.43 * *$ & -.05 & $.13^{*}$ & $.26 * *$ & $.47^{* *}$ & - & .05 & $.19 * *$ & $.16^{*}$ \\
\hline Inn & $.19 * *$ & $.24 * *$ & $.21^{* *}$ & $-.26 * *$ & $.47 * *$ & $.33^{* *}$ & $.50^{* *}$ & $.31 * *$ & - & $.60 * *$ & $.41 * *$ \\
\hline Aut & $.24 * *$ & $.27^{* *}$ & $.28^{* *}$ & $-.14^{*}$ & $.34 * *$ & $.39 * *$ & $.54 * *$ & $.41 * *$ & $.66^{* *}$ & - & $.35^{* *}$ \\
\hline Risk & $.36 * *$ & $.12^{*}$ & .07 & $-.27 * *$ & $.37 * *$ & $.19 * *$ & $.39 * *$ & $.12^{*}$ & $.55 * *$ & $.49 * *$ & - \\
\hline
\end{tabular}

Notes: ${ }^{*} p<.05 ; * * p<.01$; correlations for Spaniards above the diagonal, and correlations for Americans below the diagonal; dimensions: Extra $=$ extraversion; Agree=agreeableness; Consc $=$ conscientiousness; Neuro=neuroticism; Open=openness; Proac $=$ proactivity; Prof $=$ professional ethics; Emp $=$ empathy; Inn=innovation; Aut=autonomy; Risk=risk taking.

Figure 2

Standardized parameter estimates for the final model with personality traits predicting entrepreneurship dimensions.

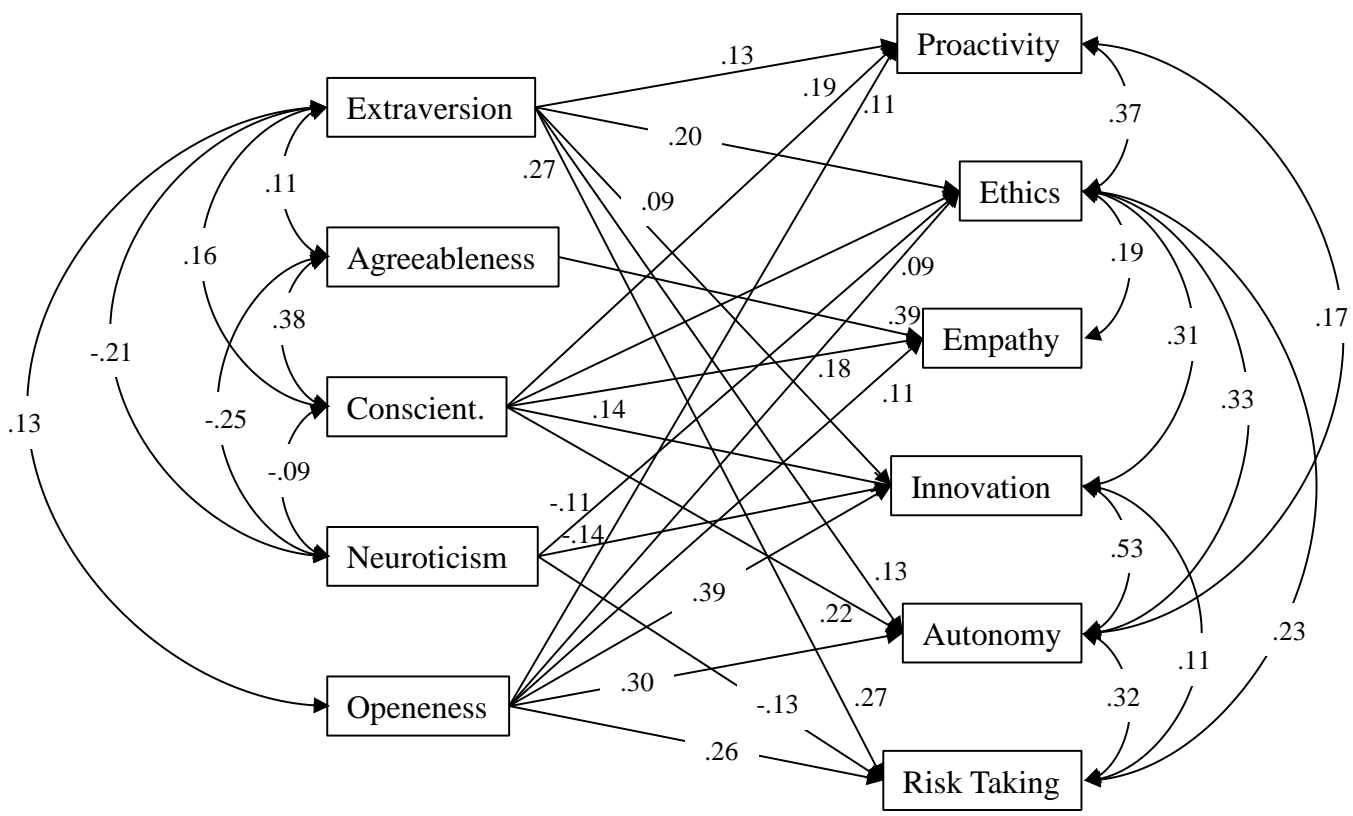

Note: All effects $p<.05$.

The initial model was tested and the model fit was extremely poor, as expected: $\chi^{2}(15)=453.36, p<.001$; $\mathrm{RMSEA}=.230 ., 90 \% \mathrm{CI}[.212-.248] ; \mathrm{CFI}=.611 ; \mathrm{SRMR}=$ .110. Therefore, the second modified model was specified as already explained. These modifications led to the model in Figure 2. This model had a very good fit: $\chi^{2}(19)=73.31, p<$ .001 ; RMSEA $=.077,90 \%$ CI [.055-.090]; CFI= .952; 
$\mathrm{SRMR}=.063$. Standardized parameter estimates for this model are shown in Figure 2.

As shown in Figure 2, the results are consistent with our hypothesis that the personality trait of openness is associated with risk taking. There was, however, no general support for the contention that conscientiousness predicts risk taking, although, as discussed later, this varied by country and gender. Neuroticism emerged as a significant negative predictor, as expected, although, as detailed later, this is tempered by cross-cultural differences. There was no overall support for our hypothesis that agreeableness would emerge as a negative correlate of risk-taking, but as reported later, there was an interesting gender $\mathrm{x}$ country interaction.

\section{Country and Gender Differences in Entrepreneur- ship}

MANOVA results revealed statistically significant differences across gender $\left(F(6,539)=12.941, p<.001, \eta^{2}=.126\right.$, Pillai's trace $=.986)$, country $\left(F(6,539)=.3 .699, p=.001, \eta^{2}\right.$ $=.040$, Pillai's trace $=.126)$ and their interaction $(F(6,539)$ $=3.675, p=.001, \eta^{2}=.039$, Pillai's trace $\left.=.039\right)$. Follow-up ANOVAs are displayed in Table 3. Gender did not have a statistically significant effect on risk-taking, but country and the interaction of gender and country did. Higher levels of proactivity and risk taking were found for Spanish people when compared to American people (see means in Table 1). Regarding the significant interaction effect, statistically significant differences were found between Spanish and American women in risk taking $(p<.001)$, with higher levels for the Spanish women. No statistically significant differences were found between Spanish and American men $(p=.606)$. These interaction effects are shown in Figure 3.

Table 3

Follow-up ANOVAs.

\begin{tabular}{lccccc}
\hline Variable & $F$ & Effect df & Error df & $p$ & $\eta^{2}$ \\
\hline 1. Gender & & & & & \\
\hline Proactivity & 11.567 & 1 & 544 & .001 & .021 \\
Professional ethics & 0.258 & 1 & 544 & .611 & .000 \\
Empathy & 24.626 & 1 & 544 & .000 & .043 \\
Innovation & 14.245 & 1 & 544 & .000 & .026 \\
Autonomy & 0.017 & 1 & 544 & .896 & .000 \\
Risk taking & 1.405 & 1 & 544 & .236 & .003 \\
\hline 2. Country & & & & & \\
Proactivity & 6.902 & 1 & 544 & .009 & .013 \\
Professional ethics & 2.128 & 1 & 544 & .145 & .004 \\
Empathy & 0.116 & 1 & 544 & .734 & .000 \\
Innovation & 0.591 & 1 & 544 & .442 & .001 \\
Autonomy & 0.334 & 1 & 544 & .563 & .001 \\
Risk taking & 9.356 & 1 & 544 & .002 & .017 \\
\hline \multicolumn{1}{l}{ 3. Gender x Country } & & & & & \\
\hline Proactivity & 3.462 & 1 & 544 & .063 & .006 \\
Professional ethics & 6.955 & 1 & 544 & .009 & .013 \\
Empathy & 4.049 & 1 & 544 & .045 & .007 \\
Innovation & 1.549 & 1 & 544 & .214 & .003 \\
Autonomy & 0.997 & 1 & 544 & .318 & .002 \\
Risk taking & 4.839 & 1 & 544 & .028 & .009 \\
\hline
\end{tabular}

Figure 3

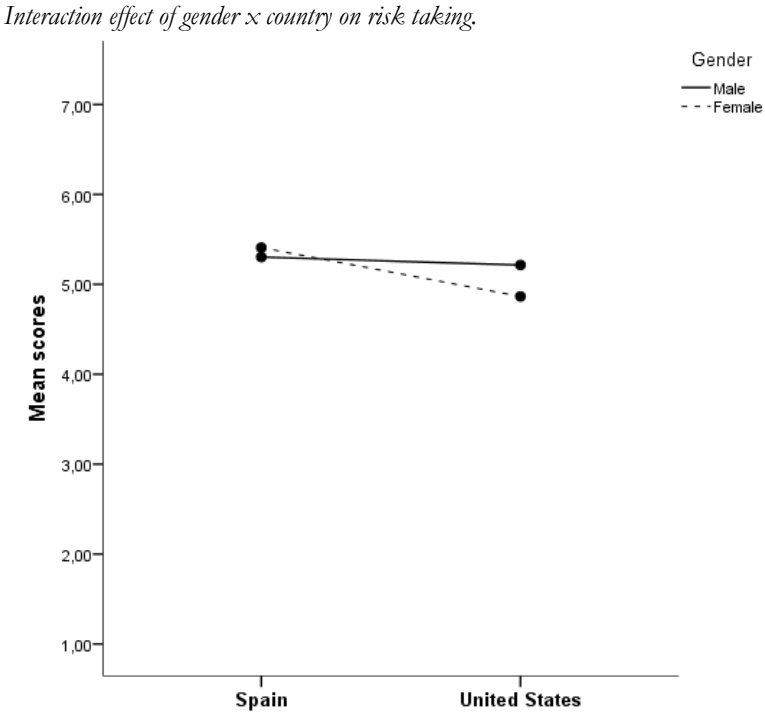

\section{Discussion}

\section{Summary of Findings}

There was partial support for our predictions regarding the main effects of personality traits. Openness to experience was associated with risk taking. Neuroticism was a negative correlate of risk taking, although this main effect is tempered by cultural differences. Contrary to predictions, the main effect of agreeableness on risk taking was not significant.

Otherwise, our findings highlight gender and cultural differences and, most saliently, the interactions of gender and culture. We only found significant positive correlations between conscientiousness and risk taking for Spanish men, in contrast with Brandstätter's (2011) findings supporting a positive association between conscientiousness and entrepreneurial success across cultures. We only found significant positive correlations between agreeableness and risk taking for Spanish men and American women; even these correlations were not large.

With regard to gender and country differences in the levels of the traits we considered, gender did not have a statistically significant effect on risk taking overall. However, there were once more significant gender $\mathrm{x}$ country interactions. The scores of Spanish women were significantly higher than those of American women. The corresponding difference between American men and women was not significant.

\section{Personality as a General Predictor in the Two Coun- tries}

Although the Big Five personality variables emerged as significant predictors of entrepreneurial attitudes in both countries, personality was a somewhat stronger predictor in the U.S. This may have occurred because of the economic 
situations of the two countries at the time of the data collection, as mentioned earlier. In a national context where there are high rates of unemployment and unsteady economic growth, there is more inherent risk in taking risks than in other places. This may reflect the reality that the variable of risk taking may describe a somewhat different person in a country where the risks of entrepreneurship are less likely to bring rewards than in a country where the proverbial "American dream" is present in people's thoughts. This is probably compounded by the high degree of central government regulation of Spain's economy, as mentioned earlier (Acemoglu \& Pischke, 1998).

\section{Specific Aspects of Personality in Relation to Risk Taking}

\section{Conscientiousness}

Significant positive correlations between conscientiousness and risk taking were found only for Spanish men, in contrast with Brandstätter's (2011) findings demonstrating a positive association between conscientiousness and entrepreneurial success across cultures. This may have to do with gender roles in Spain. López-Sáez et al. (2008) found that Spanish citizens tend to ascribe a traditional typology of trait roles to genders, with men being linked with more instrumental-agentic traits and women being linked to more expressive-communal traits. However, we found significant positive correlations between openness and risk taking across cultures and genders, as hypothesized and as reported also by Brandstätter (2011).

\section{Neuroticism}

We only found significant negative correlations between neuroticism and risk taking only for Americans, providing only partial support for our hypothesis. This cultural difference probably reflects the more general trend indicating that individual personality differences have greater predictive power in the U.S. than in Spain, where entrepreneurial attitudes may be determined to a greater extent by the surrounding context.

\section{Agreeableness}

Contrary to our hypothesis, we found small but significant positive correlations between agreeableness and risk taking only for Spanish men and American women. We believe that it is important not to over-interpret these findings because the correlations are small to begin with and because, when the results are broken down by gender and culture, the four resulting correlations straddle the conventional .05 cutoff for statistical significance. The fact that the correlations are positive suggests that risk-taking is not perceived as a phenomenon associated with people who are cold and calculating.

\section{Gender and Country Differences in Entrepreneur- ship}

Our results indicate cross-cultural differences totally diametric from the hypotheses. On the average, Spanish respondents had higher scores for proactivity and risk taking than U.S. participants. Closer inspection of the data indicates, however, that these differences are obscured by the culture $\mathrm{x}$ gender differences.

We also found higher levels of risk taking among Spanish women as compared to American women. There was little difference between the scores of Spanish women and men while American women scored much lower than American men in risk taking. These somehow counterintuitive results could be due to latest gender equality policies carried out in Spain. Being "at the vanguard in European Gender Equality Policies" (Valiente, 2008, p. 101), state feminism has been a constant of the different Spanish governments during the last 30 years.

\section{Limitations of this study}

While we took steps to ensure reliability and validity in this study, it is not free of limitations. Both our measure of personality and our measure of entrepreneurial attitudes relied entirely on self-report; because of this, they were vulnerable to self-report bias. It is possible that participants skewed their answers in certain directions, either due to a lack of accurate self-understanding or due to a desire to appear a certain way to the researchers. The surveys were completed via an anonymous online surveying system, thus limiting the chances of participants intentionally skewing responses as there was no way for researchers to match responses to specific individuals. However, the possibility of inaccuracies due to a lack of self-knowledge remains. One way to remedy this in a future study would be to include responses from multiple perspectives, such as professors or colleagues. Another limitation stemmed from the uneven gender distribution present in the samples for both countries, although this is probably quite representative of the gender distribution of psychology students. Of the American participants, only $30.4 \%$ were men, while $31.9 \%$ were men in the Spanish sample. Cultural differences in interpreting the questionnaires could have also skewed results. While efforts were taken to make the questionnaires as similar as possible despite language differences, translations always come with some slight disparities in interpretation. Our results are limited by the fact that, although the samples in both countries are first-year university students, there is an age difference of almost two years between the country samples because of differences in the length of secondary education. 


\section{Directions for Future Research}

Future studies could follow participants over time in a longitudinal design in order to examine if Big Five personality dimensions and entrepreneurial attitudes predict actual entrepreneurial activity and success. This could provide further evidence for a relationship between personality traits and entrepreneurial aptitude, as simply having entrepreneurial attitudes may not lead one to become a successful entrepreneur. Furthermore, this would add an objective measure (entrepreneurial success) which could be defined quantitatively based on the economic and social structure of the culture being examined. Future studies could also incorporate a wider age range and populations other than psychology students. Finally, future studies could analyze a wider range of cultures.

\section{Practical implications}

As mentioned earlier, the major practical application of these findings are in the area of career guidance for young people. Educators and other adults providing guidance regarding vocational choice might suggest professions requiring extensive entrepreneurial activity to people who are open to experience and conscientious. The personality trait of conscientiousness implies being careful, diligent and committed to doing things well. People displaying signs of neu-

\section{References}

Acemoglu, D., \& Pischke, J. (1998). Why do firms train? Theory and evidence. The Quarterly Journal of Economics, 113(1), 79-119. https://doi.org/10.3386/w5605.

Allik J, \&. McCrae RR. (2004). Toward a geography of personality traits: Patterns of profiles across 36 cultures. Journal of Cross-Cultural Psychology, 35, 13-28. https://doi.org/10.1177/0022022103260382

Benet-Martínez, V., \& John, O. P. (1998). Los Cinco Grandes across cultures and ethnic groups: Multitrait-multimethod analyses of the Big Five in Spanish and English. Journal of Personality and Social Psychology, 75(3), 729-750. https://doi.org/10.1037//0022-3514.75.3.729

Brandstätter, H. (2011). Personality aspects of entrepreneurship: a look at five meta-analyses. Personality and Individual Differences, 51(3), 222-230. https://doi.org/10.1016/j.paid.2010.07.007

Brockhaus, R. H. (1980). Psychological and environmental factors which distinguish the successful from the unsuccessful entrepreneur: a longitudinal study. Academy of Management Proceedings, 1980(1), 368-372. https://doi.org/10.5465/ambpp.1980.4977943

Bustelo, M. (2016). Three Decades of State Feminism and Gender Equality Policies in Multi-governed Spain. Sex Roles, 74, 107-210. https://doi.org/10.1007/s11199-014-0381-9

Byrnes, J. P., Miller, D. C., \& Schafer, W. D. (1999). Gender differences in risk taking: A meta-analysis. Psychological Bulletin, 125(3), 367-383. https://doi.org/ 10.1037//0033-2909.125.3.367

Chatterjee, S., Gupta, S.D., \& Upadhyay, P. (2018). Empowering women and stimulating development at bottom of pyramid through microentrepreneurship. Management Decision, 56, 1, 160-174. https://doi.org/10.1108/MD-04-2017-0296

Chhokar, J. S., Brodbeck, F. C., \& House, R. J. (Eds.). (2007). Culture and leadership across the world: The GLOBE book of in-depth studies of 25 societies. Mahwah, NJ: Lawrence Erlbaum Associates. https://doi.org/10.4324/9780203936665 roticism might end up dissatisfied in professions that call for entrepreneurial initiatives.

Universities and on-site training programs can systematically facilitate successful entrepreneurial activity for those who seemed inclined to enjoy it and do well at it. Among the published reports of successful entrepreneurial education is a study of entrepreneurial education in Spain by FerrerasGarcía et al. (2020). These authors report successful results using simulation exercises, workshops on start-up activities and entrepreneurship contests between teams.

It is imperative that such activities be offered to women as well as men and need not be limited to countries that have the most success to date in entrepreneurship. If the traditional stereotyped role of women in Mediterranean societies is incongruent with the notion of entrepreneurship, this seems to have changed to a considerable degree. Given the economic hardships brought on by the pandemic in all countries, effective but satisfied entrepreneurs may have a particular role to play in economic recovery. Their personalities may have a partial but important behind-the-scenes role in their entrepreneurship.

Funding: This research was partially supported by grants for exchange visits by Harvard RCC in Boston, USA, to Amparo Oliver in 2018 and by the International Mobility Research program of the University of Valencia to Barry H. Schneider in 2019.

Ferreras-García, R., Hernández-Lara, A. B., Serradell-López, E. (2020). Gender and learning results: a study on their relationship in entrepreneurship education and business plans, Studies in Higher Education. https://doi.org/10.1080/03075079.2020.1723525

Finney, S. J., \& DiStefano, C. (2006). Non-normal and categorical data in SEM. In G. R. Hancock \& R. O. Mueller (Eds.), Structural Equation Modelling: A Second Course (pp. 269-314). Information Age Publishing.

Gupta, V., \& Fernandez, C. (2009). Cross-cultural similarities and differences in characteristics attributed to entrepreneurs: A three-nation study. Journal of Leadership and Organizational Studies, 15, 304-318. https://doi.org/10.1177/1548051808326036

Hahn, D., Minola, T., Bosio, G., \& Cassia, L. (2020). The impact of entrepreneurship education on university students' entrepreneurial skills: a family embeddedness perspective. Small Business Economics, 55(1), 257 282. https://doi.org/10.1007/s11187-019-00143-y

Hayton, J. C., George, G., \& Zahra, S. A. (2002). National culture and entrepreneurship: A review of behavioral research. Entrepreneurship: Theor \& Practice, 24, 33-52. https://doi.org/10.1177/104225870202600403

Hofstede, G. (2001). Culture's Consequences: Comparing Values, Behaviors, Institutions, and Organizations Across Nations (2nd ed.). Sage Publications.

John, O.P. \& Srivastava, S. (1999) The Big Five Trait Taxonomy: History, Measurement, and Theoretical Perspectives. In: Pervin, L.A. and John, O.P. Eds., Handbook of Personality: Theory and Research, Vol. 2, Guilford Press, 102-138.

Kline, R. B. (2015). Principles and Practice of Structural Equation Modeling. Guilford.

Laurent, A. (1980). Once a Frenchman, always a Frenchman... International Management, 35, 6, 45-46.

López-Sáez, M., Morales, J.F., Lisbona, A. (2008). Evolution of gender stereotypes in Spain: traits and roles. Spanish Journal of Psychology, 11(2), 609617. https://doi.org/10.1017/s1138741600004613. 
Moral-Arce, I., Sperlich, S., Fernández-Saínz, A. I., \& Roca, M. J. (2012). Trends in the gender pay gap in Spain: A semiparametric analysis. Journal of Labor Research, 33(2), 173-195. https://doi.org/10.1007/s12122-011-9124-7

Muthén, L. K., \& Muthén, B. O. (2018). Mplus User's Guide Statistical Analysis with Latent V ariables (7th ed.). Authors.

O'Connell, J. J., Prieto, J. M., \& Gutierrez, C. (2007). Managerial culture and leadership in Spain. In. Chhokar, J.S. Brodbck, F. C. \& House, R.J. (Eds). F. C. Culture and leadership across the world: The GLOBE book of indepth studies (pp. 623-654).

Oliver, A., \& Galiana, L. (2015). Development and validation of the Escala de Actitudes Emprendedoras para Estudiantes (EAEE). The Spanish Journal of Psychology, 18, 1-10. https://doi.org/10.1017/sjp.2015.14

Rico, P., \& Cabrer-Borrás, B. (2018). Gender differences in selfemployment in Spain. International Journal of Gender and Entrepreneurship, 10(1), 19-38. https://doi.org/10.1108/IJGE-09-2017-0059

Schmitt, D. P., Allik, J., McCrae, R. R., \& Benet-Martínez, V. (2007). The geographic distribution of Big Five personality traits: Patterns and profiles of human self-description across 56 nations. Journal of Cross-Cultural Psychology, 38(2), 173-212. https://doi.org/10.1177/0022022106297299

Schmitt, D. P., Realo, A., Voracek, M., \& Allik, J. (2008). "Why can't a man be more like a woman? Sex differences in big five personality traits across 55 cultures": Correction to Schmitt et al. (2008). Journal of Personality and Social Psychology, 94(1), 168-182. https://doi.org/10.1037/a0014651
Shane, S. \& Venkataraman, S. (2000). The promise of entrepreneurship as a field of research. The Academy of Management Review. 25, 217-226. https://doi.org/10.5465/amr.2000.2791611

Teixeira, A. A., \& Vasque, R. (2020). Entrepreneurship And Happiness: Does National Culture Matter? Journal of Developmental Entrepreneurship, 25, 1. https://doi.org/10.1142/S1084946720500077

Valiente, C. (2008). Spain at the vanguard in European gender equality policies. In S. Roth (Ed.), Gender politics in the expanding European Union: Mobilization, inclusion, exclusion (pp. 101-117). Berghahn.

Weber, C. S. (2013). Cultural differences in risk tolerance. Institute of Economics, Working Paper No. https://pdfs.semanticscholar.org/74ac/1bb6f9c49b85466b4d22ac7d63 017a5f6149.pdf

Warnecke, T. (2013). Entrepreneurship and gender: An institutional perspective. Journal of Economic Issues, 47(2), 455-464. https://doi.org/10.2753/JEI0021-3624470219

Zhao, H., \& Seibert, S. E. (2006). The Big Five personality dimensions and entrepreneurial status: A meta-analytical review. Journal of Applied Psychology, 91(2), 259-271. https://doi.org/10.1037/0021-9010.91.2.259

Zhao, H., Seibert, S. E. \& Lumpkin, G. T. (2010). The relationship of personality to entrepreneurial intentions and performance: A meta-analytic review. Journal of Management, 36 (2). 381-404. https://doi.org/10.1177/0149206309335187

Zinkhan, G. M., \& Karande, K. W. (1991). Cultural and gender differences in risk-taking behavior among American and Spanish decision makers. The Journal of Social Psychology, 131(5), 741-742. https://doi.org/10.1080/00224545.1991.992465 